\title{
Incremental Diagnostic Value and Impact on Patient Management of Somatostatin Receptor Scintigraphy with Indium-111-Pentetreotide in Gastroenteropancreatic Neuroendocrine Tumors
}

\author{
Sharjeel Usmani Haider Ali Khan Maha Abdulla Najeeb Ahmed \\ Fawaz abu Huda Fahad Marafi Farida al Kandari Shihab al Mohannadi \\ Naheel al Nafisi \\ Department of Nuclear Medicine, Hussain Makki Al Jumma Center for Specialized Surgery, Ministry of Health, \\ Khaitan, Kuwait
}

\section{Key Words}

Indium-111-pentetreotide · Gastroenteropancreatic neuroendocrine tumors $\cdot$ Somatostatin receptor scintigraphy

\begin{abstract}
Objective: To evaluate the efficacy of somatostatin analog scintigraphy with indium-111-pentetreotide and its overall impact on management in patients with gastroenteropancreatic neuroendocrine tumors (GEP-NET). Subjects and Methods: Twenty-two consecutive patients with a proven or clinically suspected GEP-NET with or without proven metastases were imaged at 24 and $48 \mathrm{~h}$ after injection of ${ }^{111} \mathrm{In}$-pentetreotide. The scintigraphic findings were compared with results from conventional imaging methods. The final diagnosis was based on histopathological and surgical findings and complementary radiology. Results: Somatostatin receptor-positive lesions were found in 20 of the patients, whereas conventional methods were positive in 18 patients. Additionally, 13 new tumor sites were discovered by somatostatin receptor scintigraphy in 5 patients (liver: 6; chest: 2; bone: 1; abdomen: 4). The surgical therapeutic strategy was changed in 7 patients (32\%). Conclusions: Our data reinforced that scintigraphy with ${ }^{111} \mathrm{In}$-pentetreotide repre-
\end{abstract}

\section{KARGER}

Fax +4161306 1234

E-Mail karger@karger.ch

www.karger.com
(C) 2011 S. Karger AG, Basel

1011-7571/11/0204-0356\$38.00/0

Accessible online at:

www.karger.com/mpp sents the imaging modality of choice in the initial evaluation of GEP-NET. It is highly accurate and can identify clinically unsuspected lesions and optimize the overall staging. It also guides optimal therapy choice and most importantly identifies patients with inoperable or metastatic disease who might be candidates for high-dose targeted therapy.

Copyright $\odot 2011$ S. Karger AG, Basel

\section{Introduction}

Gastroenteropancreatic neuroendocrine tumors (GEP-NET) are relatively rare tumors which manifest as a syndrome related to uncontrolled hormone secretion by functioning tumors, or as nonspecific symptoms related to the mass effect of nonfunctioning tumors, with an overall incidence of 3-4.5 per 100,000 [1]. The first manifestations of the disease seriously affect patient prognosis. The tumors most commonly metastasize to the liver, and the presence of hepatic metastases is known to decrease the 5-year survival rate [2].

Surgery is widely accepted as first-choice therapy. In fact, even in patients with liver metastases, resection is now considered a safe procedure [3]. Cytoreductive surgery can represent a potentially curative treatment when 
metastases are still resectable [4]. For nonresectable metastases, other treatments are used, such as interferon- $\alpha$ and somatostatin analog therapy, cytotoxic chemotherapy, hepatic arterial embolization or chemoembolization, and even liver transplantation [5].

Accurate localization of the primary tumor is particularly important for appropriate management. Assessment of the extent of the tumor and disease progression is essential for making decisions about resectability and tumoricidal therapy. Many conventional imaging methods, including ultrasonography, computed tomography (CT), magnetic resonance imaging (MRI), selective arteriography and selective intra-arterial secretin stimulation with venous sampling, already exist for the localization of GEP tumors [6]. Several studies have shown that the primary lesions as well as metastases of well-differentiated GEP-NET express somatostatin receptors, especially subtype 2 [7].

Indium-111-pentetreotide binds to somatostatin receptor subtype 2 and can be used for imaging purposes [8]. Somatostatin receptor scintigraphy (SRS) is routinely performed to localize the primary tumor, evaluate disease extension, determine the receptor status as a predictor of response to octreotide therapy, and monitor treatment effects in patients selected for targeted radionuclide therapy. The reported sensitivity of SRS is $80-90 \%$, and it has been found to be superior to other diagnostic imaging methods in identifying and assessing the staging of GEP tumors, except for insulinoma [9]. SRS has been shown to upstage disease in $10-43 \%$ of patients with a modification of previous therapeutic options in some cases [10-12]. The purpose of this study was to prospectively evaluate the ability of ${ }^{111}$ In-pentetreotide scintigraphy in the detection and localization of GEP-NET and the overall impact of this diagnostic modality on patient management.

\section{Subjects and Methods}

Twenty-two patients (12 males, 10 females; mean age: $56 \pm 13$ years; range: $27-76$ years) with proven or clinically suspected GEP-NET were prospectively included in the study. During the initial diagnostic process, 19 patients with suspected GEP-NET were included in the study, while in 3 patients, the primary tumor had already been resected prior to initial SRS, but they had not received any other form of therapy. Written consent was obtained from all patients. Final diagnoses for patients considered to have a GEP tumor or metastases were based on the results of complementary radiology (CT, MRI, arteriography or endoscopic sonography) or of surgery and histology as obtained from the medical records of the patients.

Somatostatin Receptor Scintigraphy
${ }^{111}$ In-Pentetreotide Imaging

A mean dose of $110 \pm 10 \mathrm{MBq}{ }^{111}$ In-pentetreotide containing $10 \mu \mathrm{g}$ somatostatin analog was administered immediately after its specific radiochemical purity had been checked by chromatography. Scintigraphic planar images were acquired using a doubleheaded camera with a medium-energy, parallel-hole collimator, a $256 \times 256$ matrix and a preset time of $10-15 \mathrm{~min}$. Acquisition was performed using both ${ }^{111}$ In photopeaks ( 171 and $245 \mathrm{keV}$ ). Whole body images were obtained at $24 \mathrm{~h}$ after injection. Additional lateral and oblique views were obtained when considered necessary. Delayed static images of the abdomen were systematically obtained in the anterior and posterior views at $48 \mathrm{~h}$ after injection.

Single-photon emission computed tomography (SPECT) was performed after planar imaging. The SPECT acquisition parameters were: a double-indium peak acquisition, 64 projections over a 360-degree rotation, $40-60 \mathrm{~s}$ per step, and a $64 \times 64$ matrix. Tomographic slices were obtained using iterative reconstruction (2 iterations, 8 subsets) with Hanning postfilter reconstruction.

\section{Image Interpretation}

The scintigraphic images were visually analyzed, separately and independently for each scintigraphic method, by two experienced nuclear medicine physicians (H.A.K. and S.U.) who were blinded to the patients' clinical information. A consensus reading was obtained in cases of interobserver disagreement. The images were evaluated for the presence or absence of abnormal uptake.

\section{Results}

Out of the 22 patients, histopathologically, 12 had carcinoid tumor, 3 had gastrinoma, 2 had insulinoma and 1 had glucagonoma, while 4 were determined to be nonfunctional islet cell carcinoma (table 1). ${ }^{111}$ In-pentetreotide scintigraphy showed abnormal findings in 20 (91\%) out of 22 patients $(\mathrm{p}<0.005)$, while combined conventional imaging procedures (CT, MRI, arteriography or endoscopic sonography) were positive in 18 patients. Additionally, 13 new tumor sites were discovered by SRS in 5 patients (liver: 6 ; chest: 2; bone: 1 ; abdomen: 4 ) (table 1 ).

The presence of liver metastases was confirmed by histopathological examination in 10 of 22 GEP tumor patients (45\%). SPECT ${ }^{111}$ In-pentetreotide scintigraphy (fig. 1) was true positive in 9 of the above 10 patients, while planar and conventional imaging procedures were true positive in 6 and 7 patients, respectively. Thirty-nine sites (in 10 patients) were detected by ${ }^{111}$ In-pentetreotide scintigraphy, and 30 sites (in 7 patients) were detected by conventional imaging procedures.

The surgical therapeutic strategy was changed in $7 \mathrm{pa}-$ tients (32\%) as a direct result of SRS findings. In 3 patients, SRS showed only 1 or 2 liver metastases, and curative surgery of the primary tumor along with liver surgery was therefore thought to be a valid option. SRS revealed extra- 
Fig. 1. ${ }^{111}$ In-pentetreotide. a Whole body images. b SPECT images. Multiple focal areas of increased tracer uptake in the liver (arrows) suggest metastases.

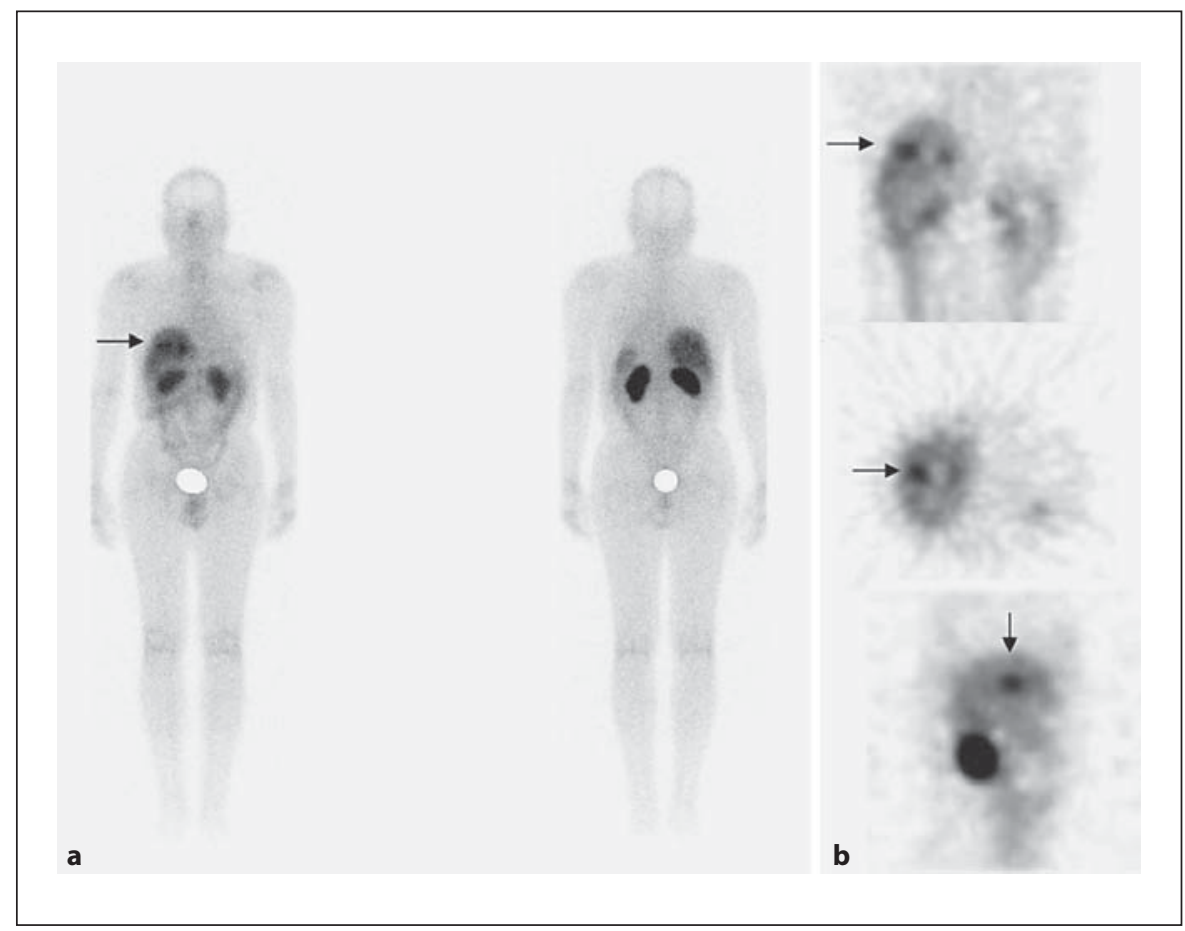

Table 1. Patient characteristics, SRS findings and their impact on management

\begin{tabular}{|c|c|c|c|c|c|c|}
\hline \multirow{2}{*}{$\begin{array}{l}\text { Patient } \\
\text { No. }\end{array}$} & \multirow{2}{*}{$\begin{array}{l}\text { Age, } \\
\text { years }\end{array}$} & \multirow[t]{2}{*}{ Sex } & \multirow[t]{2}{*}{ Primary tumor type } & \multicolumn{3}{|l|}{ SRS } \\
\hline & & & & finding sites & impact on surgery & therapeutic decision \\
\hline 1 & 60 & M & islet cell pancreatic tumor & pancreas & surgery confirmed & surgery \\
\hline 2 & 46 & $\mathrm{~F}$ & islet cell pancreatic tumor & pancreas, liver, abdomen ${ }^{1}$ & surgery rejected & octreotide therapy + chemotherapy \\
\hline 3 & 65 & $\mathrm{~F}$ & gastrinoma & pancreas, stomach, abdomen ${ }^{1}$ & surgery rejected & octreotide therapy + chemotherapy \\
\hline 4 & 67 & $\mathrm{~F}$ & insulinoma & pancreas & surgery confirmed & surgery \\
\hline 5 & 39 & M & carcinoid & ileum & surgery confirmed & surgery \\
\hline 6 & 27 & M & gastrinoma & pancreas & surgery confirmed & surgery \\
\hline 7 & 56 & M & carcinoid (R) & liver $^{2}$ & surgery confirmed & surgery twice $^{2}+$ octreotide therapy started \\
\hline 8 & 47 & $\mathrm{M}$ & islet cell pancreatic tumor & pancreas & surgery confirmed & surgery \\
\hline 9 & 55 & $\mathrm{~F}$ & carcinoid $(\mathrm{R})$ & liver $^{2}$ & surgery confirmed & surgery $^{2}+$ octreotide therapy started \\
\hline 10 & 64 & $\mathrm{~F}$ & carcinoid & rectum & surgery confirmed & surgery \\
\hline 11 & 58 & M & carcinoid (R) & liver $^{2}$ & surgery confirmed & surgery $^{2}+$ octreotide therapy started \\
\hline 12 & 72 & M & carcinoid & ileum, liver, mesenteric nodes ${ }^{1}$ & surgery rejected & octreotide therapy + chemotherapy \\
\hline 13 & 68 & M & carcinoid & no lesion & - & surgery \\
\hline 14 & 39 & $\mathrm{~F}$ & glucagonoma & pancreas & surgery confirmed & surgery \\
\hline 15 & 65 & $\mathrm{~F}$ & islet cell pancreatic tumor & pancreas & surgery confirmed & surgery \\
\hline 16 & 72 & $\mathrm{~F}$ & carcinoid & liver $^{2}$ & surgery confirmed & no surgery ${ }^{3}$, octreotide therapy started \\
\hline 17 & 49 & M & carcinoid & ileum, liver, chest $^{1}$ & surgery rejected & octreotide therapy + chemotherapy \\
\hline 18 & 32 & M & carcinoid & rectum & surgery confirmed & surgery \\
\hline 19 & 58 & M & insulinoma & no lesion & - & surgery \\
\hline 20 & 76 & $\mathrm{~F}$ & carcinoid & liver $^{2}$ & surgery confirmed & no surgery ${ }^{3}$, octreotide therapy started \\
\hline 21 & 55 & M & gastrinoma & pancreas & surgery & surgery \\
\hline 22 & 62 & $\mathrm{~F}$ & carcinoid & ileum, liver, chest $^{1}$, bone ${ }^{1}$ & surgery rejected & $\begin{array}{l}\text { octreotide therapy }+ \text { chemotherapy }+ \\
\text { radiotherapy }\end{array}$ \\
\hline
\end{tabular}

$\mathrm{R}=$ Primary tumor already resected prior to initial SRS.

${ }^{1}$ Confirmed new sites identified by SRS. ${ }^{2}$ Another curative liver surgery was performed as a direct result of SRS. ${ }^{3}$ Surgery not performed due to poor medical condition. 
Fig. 2. ${ }^{111}$ In-pentetreotide whole body images (a) and spot view of the abdomen (b) show focal areas of increased tracer uptake at the mid abdomen (primary site at the pancreas; solid arrows). Focal areas of increased tracer uptake are also seen in the liver, suggesting metastases (dashed/dotted arrows).

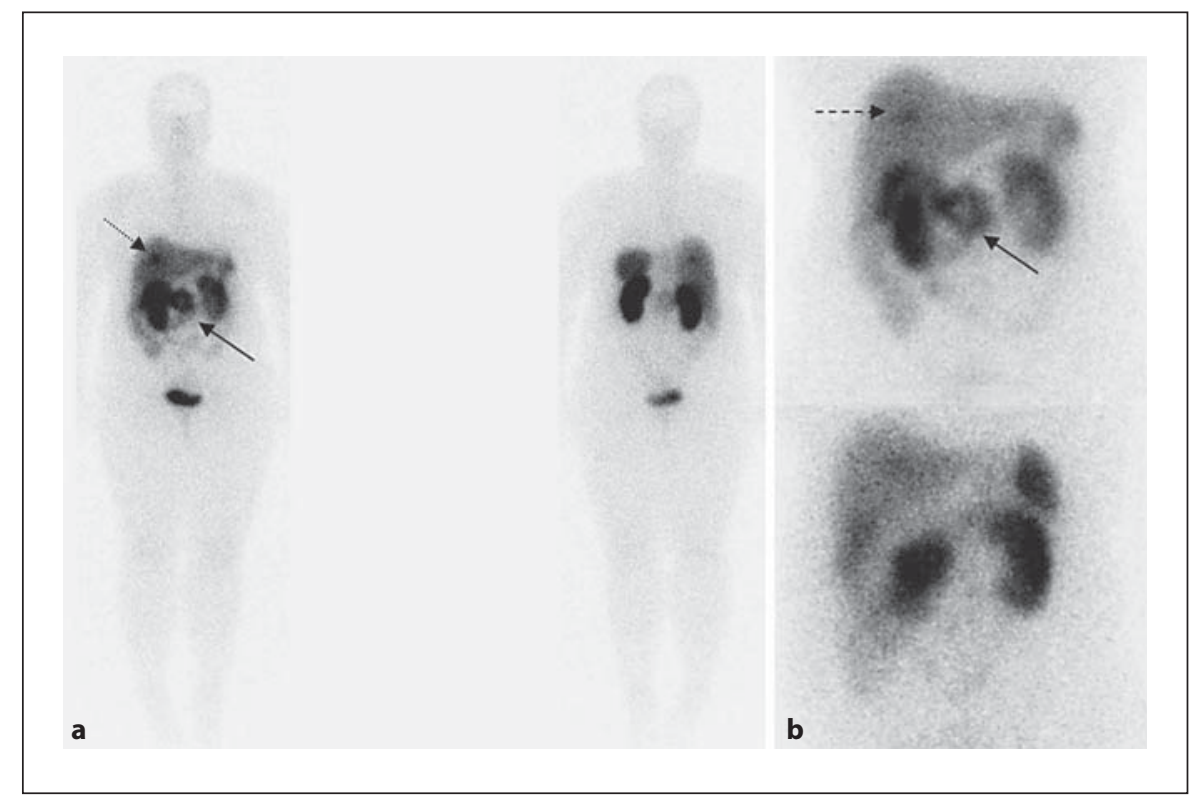

hepatic metastases in 4 patients, and in these patients, the curative surgery was abandoned (fig. 2, 3).

Twenty patients were positive by SRS and therefore susceptible to benefit from octreotide therapy. Following scintigraphy, octreotide therapy was started in 12 patients. In 5 cases, the clinician did not consider octreotide therapy. Three patients underwent curative surgery in the form of removal of the primary tumor and associated resectable liver metastases.

\section{Discussion}

In our study, SRS proved to be of major clinical significance, and it altered the surgical therapeutic strategy for 7 patients (32\%). Our results are in agreement with those by Lebtahi et al. [13], who confirmed previous reports [13, 14] that SRS is able to induce a change in the clinical management of a significant proportion of $21-53 \%$ of patients with GEP tumors. Therefore, performing SRS has become essential for the proper management of patients with different types of GEP tumors, and it is now recommended as the initial imaging modality for these neoplasms [14].

GEP tumors are characterized by a high to very high incidence and density of somatostatin receptors of the sst $_{2 \mathrm{~A}}$ type. The very high sensitivity of SRS permits the detection of not only very small primary tumors but also small metastases, which explains why it often modifies patient classification and therapeutic strategy [15]. The impact of SRS on patient management is manifold as it may detect resectable tumors that would be unrecognized by conventional imaging techniques and may prevent surgery in patients whose tumors have metastasized to a greater extent but the lesions are still too small to be characterized by conventional imaging. SRS is also used to select patients for cold octreotide therapy. The whole body imaging technique may provide valuable information about unsuspected metastatic disease. SRS is also important for assessing patients' suitability for radiolabeled somatostatin analog therapy and for monitoring the response to that therapy.

In our study, 13 new tumor sites were discovered by SRS in 5 patients, thus leading to a change in classification of these patients similar to that described by Chiti et al. [12], who reported that SRS detected new lesions in $28 \%$ of cases and modified the therapeutic schedule in $21 \%$. The surgical therapeutic strategy was changed in 7 patients (32\%) as a direct result of SRS findings.

${ }^{111}$ In-pentetreotide SRS is a sensitive method of localizing liver metastases in patients with GEP tumors, with a reported sensitivity of $80-100 \%[16,17]$. Our study is in agreement with previous reports that SPECT is more sensitive for the detection of focal lesions than planar and conventional imaging. SPECT has better contrast resolution than planar imaging, which accounts for its enhanced sensitivity [18]. Nevertheless, despite this high sensitivity to most GEP tumors, the ability of SRS to visualize tumor sites in vivo is closely related to their size 
Fig. 3. a, b ${ }^{111}$ In-pentetreotide whole body images and spot view image show multiple focal lesions at the posterior mediastinum and in the liver (solid arrows). c SRS discovered bone metastases at the right sacroiliac joint (dashed arrow). d The corresponding bone scan also shows this uptake is in the right sacroiliac joint (dashed arrow).

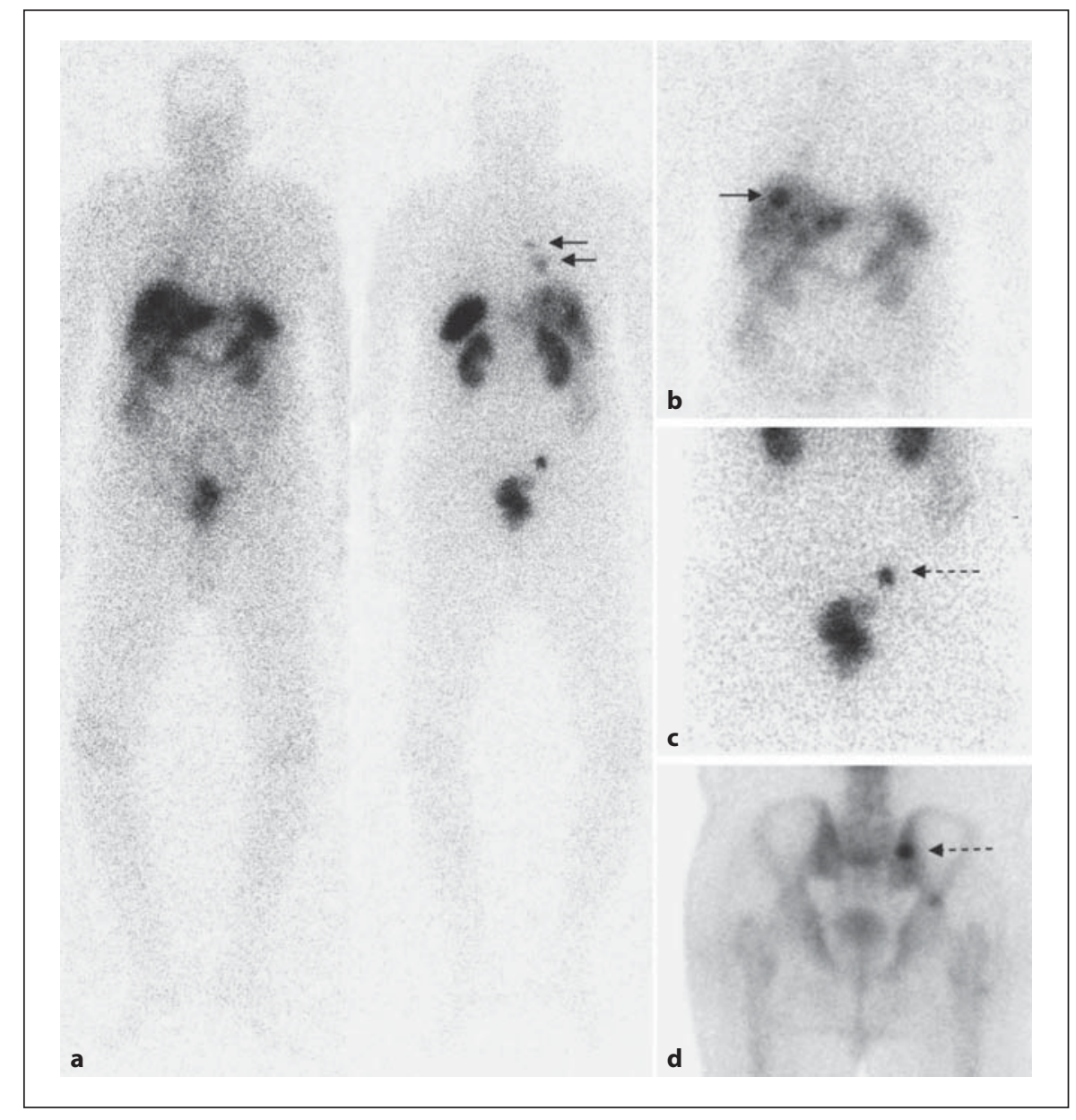

and is limited especially for lesions of $\leq 1 \mathrm{~cm}$ (both primary and metastatic lymph-nodal and hepatic lesions) [19]. Moreover, other limiting factors are modifications in local tumor blood supply, unlabeled endogenous somatostatin resulting in competition with - or downregulation of - the somatostatin receptors, and expression of receptor subtype pattern with less affinity for the radioligand [20]. In our study, the specificity of SRS imaging was $100 \%$ (no false-positive case). The reported specificity of SRS is high (90\%), but it can be significantly affected by the physiologic biodistribution of the radiopharmaceutical related to the receptor status of target tissues or to its elimination route via the kidneys and gastrointestinal tract [21]. Because SRS like other radionuclide images lacks anatomical definition, which frequently makes it difficult to precisely localize a focus of abnormal accumulation and identify structures displaying normal activity, the fusion of SPECT and CT images might resolve this problem by improving image interpretation [22].
${ }^{18} \mathrm{~F}$-fluorodeoxyglucose positron emission tomography (PET) frequently fails to visualize tumors with a low proliferation rate, such as NET [23]. The development of new PET radiopharmaceuticals for detecting NET is of great interest $[24,25] .{ }^{68} \mathrm{Ga}$-DOTATOC PET is one of the promising new tools for evaluating patients with NET, showing a high diagnostic accuracy superior to conventional SRS. It is likely that this tracer will be routinely used in the near future [26].

\section{Conclusions}

In our study, SRS substantially changed the management of a number of patients. SRS is a useful diagnostic tool which is very reliable for correct staging and in selecting the most appropriate therapeutic strategy, especially for patients with liver metastases. 


\section{References}

1 Barakat MT, Meeran K, Bloom SR: Neuroendocrine tumours. Endocr Relat Cancer 2004; 11:1-18.

-2 Madeira I, Terris B, Voss M, Denys A, Sauvanet A, Flejou JF, Vilgrain V, Belghiti J, Bernades P, Ruszniewski P: Prognostic factors in patients with endocrine tumors of the duodenopancreatic area. Gut 1998;43:422-427.

-3 Nave H, Mössinger E, Feist H, Lang H, Raab $\mathrm{H}$ : Surgery as primary treatment in patients with liver metastases from carcinoid tumors: a retrospective, unicentric study over 13 years. Surgery 2001;129:170-175.

4 Nagorney DM, Que FG: Cytoreductive hepatic surgery for metastatic gastrointestinal neuroendocrine tumors; in Mignon M, Jensen RT (eds): Endocrine Tumors of the Pancreas. Recent Advances in Research and Management. Basel, Karger, 1995, pp 416430.

5 Arnold R, Frank M: Systemic chemotherapy for endocrine tumors of the pancreas: recent advances; in Mignon M, Jensen RT (eds): Endocrine Tumors of the Pancreas. Recent Advances in Research and Management. Basel, Karger, 1995, pp 431-438.

6 Orbuch M, Doppman JL, Strader DB, Fishbeyn VA, Benya RV, Metz DC, Jensen RT: Imaging for pancreatic endocrine tumor localization: recent advances; in Mignon $\mathrm{M}$, Jensen RT (eds): Endocrine Tumors of the Pancreas. Recent Advances in Research and Management. Basel, Karger, 1995, pp 268 281.

$>7$ Hofland LJ, Lamberts SW, van Hagen PM, Reubi JC, Schaeffer J, Waaijers M, van Koetsveld PM, Srinivasan A, Krenning EP, Breeman WA: Crucial role for somatostatin receptor subtype 2 in determining the uptake of ${ }^{[111}$ In-DTPA-D-Phe $\left.{ }^{1}\right]$ octreotide in somatostatin receptor-positive organs. J Nucl Med 2003;44:1315-1321.

8 John M, Meyerhof W, Richter D, Waser B, Schaer JC, Scherübl H, Boese-Landgraf J, Neuhaus P, Ziske C, Mölling K, Riecken EO, Reubi JC, Wiedenmann B: Positive somatostatin receptor scintigraphy correlates with the presence of somatostatin receptor subtype 2. Gut 1996;38:33-39. $\checkmark 9$ Ricke J, Klose KJ, Mignon M, Oberg K, Wiedenmann B: Standardisation of imaging in neuroendocrine tumours: results of a European delphi process. Eur J Radiol 2001;37: 8-17.

10 Scherübl H, Bäder M, Fett U, Hamm B, Schmidt-Gayk H, Koppenhagen K, Dop FJ, Riecken EO, Wiedenmann B: Somatostatinreceptor imaging of neuroendocrine gastroenteropancreatic tumors. Gastroenterology 1993; 105:1705-1709.

11 Jamar F, Fiasse R, Leners N, Pauwels S: Somatostatin receptor imaging with indium111-pentetreotide in gastroenteropancreatic neuroendocrine tumors: safety, efficacy and impact on patient management. J Nucl Med 1995;36:542-549.

12 Chiti A, Fanti S, Savelli G, Romeo A, Bellanova B, Rodari M, van Graafeiland BJ, Monetti N, Bombardieri E: Comparison of somatostatin receptor imaging, computed tomography and ultrasound in the clinical management of neuroendocrine gastro-entero-pancreatic tumours. Eur J Nucl Med 1998;25:1396-1403.

13 Lebtahi R, Cadiot G, Sarda L, Daou D, Fa raggi $M$, Petegnief $Y$, Mignon $M$, le Guludec D: Clinical impact of somatostatin receptor scintigraphy in the management of patients with neuroendocrine gastroenteropancreatic tumors. J Nucl Med 1997;38:853-858.

14 Gibril F, Jensen RT: Diagnostic uses of radiolabelled somatostatin receptor analogues in gastroenteropancreatic endocrine tumours. Dig Liver Dis 2004;36(suppl 1):S106-S120.

15 Krausz Y, Bar-Ziv J, de Jong RB, Ish-Shalom S, Chisin R, Shibley N, Glaser B: Somatostatin-receptor scintigraphy in the management of gastroenteropancreatic tumors. Am J Gastroenterol 1998;93:66-70.

16 Chiti A, Briganti V, Fanti S, Monetti N, Masi $\mathrm{R}$, Bombardieri E: Results and potential of somatostatin receptor imaging in gastroenteropancreatic tumors. Q J Nucl Med 2000; 44:42-49.

17 Reubi JC: Somatostatin and other peptide receptors as tools for tumor diagnosis and treatment. Neuroendocrinology 2004;80: 51-56.
18 Schillaci O, Spanu A, Scopinaro F, Falchi A, Danieli R, Marongiu P, Pisu N, Madeddu G, delle Fave G, Madeddu G: Somatostatin receptor scintigraphy in liver metastasis detection from gastroenteropancreatic neuroendocrine tumors. J Nucl Med 2003;44:359368.

19 Schillaci O, Scopinaro F, Angeletti S, Tavolaro R, Danieli R, Annibale B, Gualdi G, delle Fave G: SPECT improves accuracy of somatostatin receptor scintigraphy in abdominal carcinoid tumors. J Nucl Med 1996; 37:1452-1456.

20 Balon HR, Goldsmith SJ, Siegel BA, Silberstein EB, Krenning EP, Lang O, Donohoe KJ: Procedure guideline for somatostatin receptor scintigraphy with ${ }^{111}$ In-pentreotide. J Nucl Med 2001;42:1134-1138.

21 Gibril F, Reynolds JC, Chen CC, Yu F, Goebel SU, Serrano J, Doppman JL, Jensen RT: Specificity of somatostatin receptor scintigraphy: a prospective study and effects of false-positive localizations on management in patients with gastrinomas. J Nucl Med 1999;40:539-553.

22 Schillaci O: Functional-anatomical image fusion in neuroendocrine tumors. Cancer Biother Radiopharm 2004;19:129-134.

23 Kaltsas G, Rockall A, Papadogias D, Resnek $\mathrm{R}$, Grossman AB: Recent advances in radiological and radionuclide imaging and therapy of neuroendocrine tumours. Eur J Endocrinol 2004;151:15-27.

24 Adams S, Baum R, Rink T, Schumm-Dräger PM, Usadel KH, Hör G: Limited value of fluorine-18 fluorodeoxyglucose positron emission tomography for the imaging of neuroendocrine tumours. Eur J Nucl Med 1998;25:79-83.

25 Rufini V, Calcagni ML, Baum RP: Imaging of neuroendocrine tumors. Semin Nucl Med 2006;36:228-247.

26 Gabriel M, Decristoforo C, Kendler D, Dobrozemsky G, Heute D, Uprimny C, Kovacs $\mathrm{P}$, von Guggenberg E, Bale R, Virgolini IJ: ${ }^{68} \mathrm{Ga}$-DOTA-Tyr ${ }^{3}$-octreotide PET in neuroendocrine tumors: comparison with somatostatin receptor scintigraphy and CT. J Nucl Med 2007;48:508-518. 